\title{
3 Positive Change and Positive Technology
}

\begin{abstract}
Cyberpsychology is a recent branch of psychology that is driven by the quest to help humans deal with their digital environments. The object of study in cyberpsychology, as it is for much Human-Computer Interaction research, is the change introduced by the technology and not the technology itself. In particular, it aims at the understanding, forecasting and activation of the different processes of change related to the use of new technologies. However, within this broad focus cyberpsychology has two faces. On one side, cyberpsychology tries to understand how technologies can be used to induce clinical change (cybertherapy). On the other side, cyberpsychology focuses on the possible use of technology for improving personal development and well-being (positive technology).In this chapter we introduced and described the "Positive Technology" approach: the scientific and applied approach for the use of technology in improving the quality of our personal experience through its structuring, augmentation and/or replacement - as a way of framing a suitable object of study in the field of personal change. First, we suggest that it is possible to use technology to manipulate the quality of experience, with the goal of increasing wellness, and generating strengths and resilience in individuals, organizations and society. Then we will classify positive technologies according to their effects on these three features of personal experience - Hedonic: technologies used to induce positive and pleasant experiences; Eudaimonic: technologies used to support individuals in reaching engaging and self-actualizing experiences; Social/Interpersonal: technologies used to support and improve the connectedness between individuals, groups, and organizations. Finally, for each level we have identified critical variables - affect regulation for the Hedonic, flow and presence for the Eudaimonic; social presence, collective intentions and networked flow for the Social/Interpersonal - that can be manipulated and controlled to guide the design and development of positive technologies.
\end{abstract}

Keywords: Cyberpsychology; Cybertherapy; Positive technology; Hedonic; Eudaimonic, Social Flow; Interpersonal Flow; Social presence; Collective intentions; Networked flow.

\subsection{Introduction: The Growing Role of Technology in Our Life}

Emerging technologies - the Internet, mobile devices, virtual reality, etc. - have greatly improved our lives (Castelnuovo, Gaggioli, Mantovani, \& Riva, 2003; Preziosa, Grassi, Gaggioli, \& Riva, 2009; Riva \& Mantovani, 2012). However, integration of 
technology in every sphere of our life is also changing us. But how is it changing us and why?

Cyberpsychology is a recent branch of psychology that is trying to answer these questions. Cyberpsychology originated in human sciences, and is driven by the quest to help humans deal with their digital environments. The object of study in cyberpsychology, as it is for much Human-Computer Interaction research, is the change introduced by the technology and not the technology itself. In particular, it aims at the understanding, forecasting and activation of the different processes of change related to the use of new technologies.

Journals such as "CyberPsychology, Behavior and Social Networking”, "Computers in Human Behaviors", "IEEE Transactions on Biomedical Engineering”, "Journal of Cybertherapy and Rehabilitation", "Journal of Medical Internet Research", "Telemedicine and e-health", are dedicated to reporting progress in this field.

Within this broad focus, however, cyberpsychology has two faces. On one side, cyberpsychology tries to understand how technologies can be used to induce clinical change (cybertherapy). On the other side, cyberpsychology focuses on the possible use of technology for improving personal development and well-being (positive technology).

In this chapter we will focus on positive technology. Specifically, we will introduce and describe the "Positive Technology" approach - the scientific and applied approach to the use of technology for improving the quality of our personal experience through its structuring, augmentation and/or replacement - as a way of framing a suitable object of study in the field of personal change (Graffigna, Barello, Wiederhold, Bosio, \& Riva, 2013; Riva, 2012b; Riva, Banos, Botella, Wiederhold, \& Gaggioli, 2012; Wiederhold \& Riva, 2012). Specifically, we suggest that it is possible to use technology to influence three specific features of our experience - affective quality, engagement/actualization and connectedness - that serve to promote adaptive behaviors and positive functioning (Graffigna, Barello, \& Riva, 2013a, 2013c). In this framework, positive technologies are classified according to their effects on a specific feature of personal experience. Moreover, for each level we have identified critical variables that can be manipulated to guide the design and development of positive technologies.

\subsection{From Positive Psychology to Positive Technology}

Psychologists started recognizing that the discipline's focus on helping people with mental health problems, specifically the diagnostic-treatment model, left many outside their scope. Early in the last decade, psychologists such as Seligman and Csikszentmihalyi proposed to increase the attention on developing well-being (Seligman \& Csikszentmihalyi, 2000). Positive psychology, as they called it, aims at understanding human strengths and virtues, and to promote these strengths to allow individuals, 
communities, and societies to flourish (Aspinwall \& Staudinger, 2003; Seligman \& Csikszentmihalyi, 2000).

Specifically, in Positive Psychology we can find two different conceptions of wellbeing, namely "subjective well-being" (also called "hedonic well-being") and "psychological well-being" (also called "eudaimonic well-being”). The first position refers to a person's subjective evaluation of his life satisfaction, and of his positive and negative emotional feelings. In contrast with subjective well-being, psychological wellbeing links happiness with lifelong conduct aimed at self-development. Whereas psychological well-being focuses on the challenges faced by adults in their private lives, social well-being concerns the tasks encountered by adults in their social structures and communities (Keyes \& Haidt, 2003).

Since then the field of positive psychology has flourished. In his book "Authentic Happiness" Seligman talked about the "three pillars" of a good life (Seligman, 2002):

- the pleasant life: achieved through the presence of positive emotions;

- the engaged life: achieved through engagement in satisfying activities and utilization of one's strengths and talents;

- the meaningful life: achieved through serving a purpose larger than oneself.

- Notwithstanding its fast growth, some have underlined that positive psychology has relevant methodological limitations related to the focus and the length of most studies (McNulty \& Fincham, 2012). To address this issue, Riva recently suggested that positive psychology may be the science of personal experience (Riva, 2012a) in that its aim should be understanding of how it is possible to manipulate the quality of personal experience with the goals of increasing wellness and generating strengths and resilience in individuals, organizations, and society.

In this view, positive functioning is a combination of three types of well-being (Keyes \& Lopez, 2002) - high emotional well-being; high psychological well-being; and high social well-being - that are achieved through the manipulation of three characteristics of our personal experience - affective quality, engagement/actualization and connectedness.

Riva and colleagues (Riva, 2012b; Riva et al., 2012; Gaggioli \& Riva, 2014) also suggested that it is possible to combine the objectives of Positive Psychology with enhancements of Information and Communication Technologies (ICTs) towards a new paradigm: Positive Technology. The main objective of this new paradigm is to use technology to manipulate and enhance the features of our personal experience for increasing wellness, and generating strength and resilience in individuals, organizations and society (Wiederhold \& Riva, 2012). In the proposed framework (see Figures 1 and 2), positive technologies are classified according to their effects on the above features of personal experience (Botella et al., 2012):

- Hedonic: technologies used to induce positive and pleasant experiences.

- Eudaimonic: technologies used to support individuals in reaching engaging and self-actualizing experiences. 
- Social/Interpersonal: technologies used to support and improve social integration and/or connectedness between individuals, groups, and organizations.

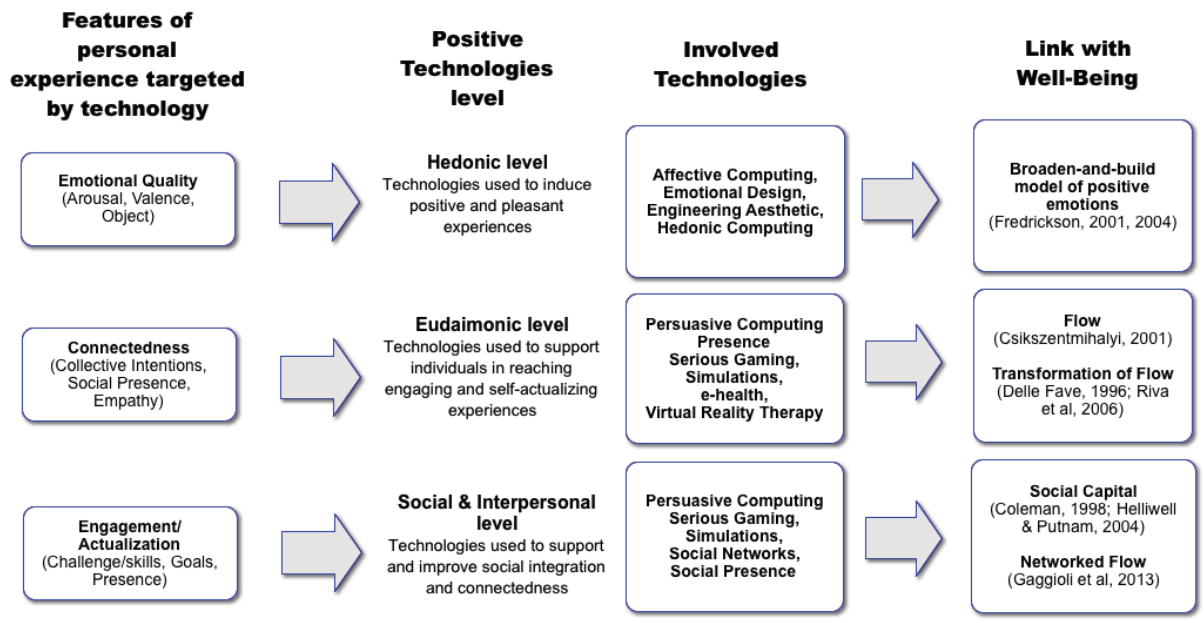

Figure 3.1: Positive Technology levels (Adapted from Riva et al., 2012)

\subsection{Hedonic Level: Using Technology to Foster Positive Emotional States}

The first dimension of Positive Technology concerns how to use technology to foster positive emotional states. According to the model of emotions developed by James Russell (2003) it is possible to modify the affective quality of an experience through the manipulation of "core affect", a neurophysiological category corresponding to the combination of valence and arousal levels that endow the subjects with a kind of "core knowledge" about the emotional features of their experience.

The "core affect" can be experienced as freefloating (mood) or attributed to some cause (and thereby begins an emotional episode). In this view, an emotional response is the attribution of a change in the core affect given to a specific object (affective quality). Simply put, a positive emotion is achieved by increasing the valence (positive) and arousal (high) of core affect (affect regulation) and by attributing this change to the contents of the proposed experience (object).

Key arguments for the usefulness of positive emotions in increasing well-being have been recently provided by Fredrickson (Fredrickson, 2001, 2004) in what she called the "broaden-and-build model" of positive emotions. According to Fredrickson, positive emotions provide the organism with nonspecific action tendencies 
that can lead to adaptive behavior (Fredrickson, 2001). For example, in children joy is associated with the urge to play, whereas interest sparks the urge to explore; in adults, positive emotions make them more likely to interact with others, provide help to others in need, and engage in creative challenges. The second proposition of Fredrickson's model concerns the consequences of the positive emotions: as discussed in the first chapter, by broadening an individual's awareness and thought - action repertoire, they build upon the resultant learning to create future physical, psychological and social resources (Fredrickson, 2004).

In literature it is possible to find many different approaches to hedonic technologies. For example, Riva and colleagues (2007) investigated how the content of interactive media, in particular virtual reality (VR), can be manipulated to induce specific emotional responses, including positive moods. The results suggested the efficacy of VR as an affective medium: the interaction with "anxious" and "relaxing” virtual environments produced anxiety and relaxation.

In a subsequent study, Villani and colleagues (Villani, Lucchetta, Preziosa, \& Riva, 2009; Villani, Riva, \& Riva, 2007) compared the efficacy of structured experiences provided through different technologies (video, audio and VR) for inducing relaxing states. The results of this experiment showed a significant reduction in anxiety and a significant improvement in positive emotional states, measured through self-report questionnaires and physiological parameters, but no difference among the media conditions. However, findings highlighted a significant correlation between changes in emotional states and factors related to the sense of presence felt by participants during media exposure.

\subsection{The Eudaimonic Level: Using Technology to Promote Engage- ment and Self-Empowerment}

The second level of Positive Technology is strictly related to the eudaimonic concept of well-being, and consists of investigating how technologies can be used to support individuals in reaching engaging and self-actualizing experiences.

The theory of flow, developed by Positive Psychology pioneer Mihaly Csikszentmihalyi (1990), provides a useful framework for addressing this challenge. As discussed in the first chapter Flow or optimal experience is a positive and complex state of consciousness that is present when individuals act with total involvement. The basic feature of this experience is the perceived balance between high environmental opportunities for action (challenges) and adequate personal resources in facing them (skills). Additional characteristics are deep concentration, clear rules in and unambiguous feedback from the task at hand, loss of self-consciousness, control of one's actions and environment, positive affect and intrinsic motivation.

The theory of flow has been extensively used to study user experience with information and communication technologies. Ghani (Ghani \& Deshpande, 1994) 
identified three factors that influence the occurrence of flow in human-computer interaction: perceived control, fitness of task (i.e., the difference between challenges and skills), and cognitive spontaneity ("playfulness"). According to Ghani's model, the experience of flow can produce positive cognitive effects in users, such as an augmented focus on the process, increased creativity, and enhanced learning.

Among the different types of interactive technologies investigated so far by flow researchers, immersive systems such as VR are considered the most capable of supporting the emergence of this experience (Gaggioli, Bassi, \& Delle Fave, 2003; Riva, Castelnuovo, \& Mantovani, 2006; Riva et al., 2010). Research conducted thus far highlights some key characteristics of this technology as a source of flow: (a) opportunities for action (goals and rules) - due to its flexibility, VR provides designers with the possibility of creating a wide range of increasingly challenging situations and tasks, (b) feedback - VR systems can offer multimodal feedback to individuals' actions and behavior (Gaggioli, 2004; Gaggioli et al., 2003). Some researchers have drawn parallels between the experience of flow in VR and the sense of presence, defined as the subjective perception of "being there" in a virtual environment (Heeter, 2003; Riva, 2009a; Riva, Waterworth, \& Waterworth, 2004; Riva, Waterworth, Waterworth, \& Mantovani, 2011; Zahoric \& Jenison, 1998). From the phenomenological viewpoint, both experiences have been described as absorbing states, characterized by a merging of action and awareness, loss of self-consciousness, a feeling of being transported into another reality, and an altered perception of time (Waterworth, Waterworth, Mantovani, \& Riva, 2010). Further, both presence and optimal experience are associated with high involvement, focused attention and high concentration on the ongoing activity (Marsh, 2003). In particular, Riva and Waterworth (Riva et al., 2011; Waterworth et al., 2010) have argued that there is a correspondence between “maximal” presence and optimal experience. Drawing on Damasio's (1999) three-fold model of self (proto-self, core-self, and extended self), these authors have suggested that "optimal presence" arises when the three components of the self are combined with an abnormally tight focus on the same content, so that intentions and action are directed exclusively towards the current external situation.

Starting from these theoretical premises, Riva and colleagues (Riva, 2009b,c; Riva et al., 2006) have suggested the possibility of using VR for a new breed of applications in positive mental health, based on a strategy defined as "transformation of flow", defined as a person's ability to draw upon an optimal experience induced by technology, and use it to promote new and unexpected psychological resources and sources of involvement (see also Chapter 2).

This strategy, that integrates the Fredrickson's “broaden-and-build model” with "flow" theory, involves three main steps (Riva et al., 2006; Riva, Mantovani, \& Gaggioli, 2004). First, it is necessary to identify an information-rich environment that contains functional real-world demands; second, to use the technology to enhance the level of presence of the subject in the environment and to induce an optimal experience; third, to allow cultivation by linking this optimal experience to the actual 
experience of the subject. As underlined by Gaggioli and colleagues (2003), to maintain the balance between high challenges and skills that characterize optimal experience, the individual will search for increasingly complex opportunities for action leading to the progressive improvement of related skills. By virtue of this dynamic process of skills cultivation and increasing levels of challenges, optimal experience influences individual development through the building of a life theme, namely the set of goals and interests a person preferentially pursues and cultivates in his/her life.

\subsection{The Social and Interpersonal Level: Using Technology to Promote Social Integration and Connectedness}

The final level of Positive Technology - the social and interpersonal one - is concerned with the use of technologies to support and improve the connectedness between individuals, groups, and organizations. However, an open challenge is to understand how to use technology to create a mutual sense of awareness, which is essential to the feeling that other participants are there, and to create a strong sense of community at a distance. Short et al., (1976) define 'social presence' as the "degree of salience of the other person in a mediated communication and the consequent salience of their interpersonal interactions" (p. 65). Conventional computer-mediated communicative tools, such as email or text-based chat, are regarded as having lower social presence and social context cues when compared to face-to-face communication. However, different authors have suggested that it is possible to manipulate the technological experience to enhance social presence and thereby improve different mediated activities (Park, 2010) such as online learning (Joyce, 2009), e-commerce (Swamynathan, Wilson, Boe, Almeroth, \& Zhao, 2008) and health care (Boulos \& Wheeler, 2007).

Riva and colleagues $(2010 ; 2014)$ recently suggested that a subject is present within a virtual group if he is able to put his own intentions (presence) into practice and to understand the intentions of the other group members (social presence). This implies that, as discussed in Chapter 4, to sustain social optimal experiences (networked flow), the technology has to provide the virtual group with the possibility of expressing itself and of understanding what each individual member is doing (Riva, 2004). More, Gaggioli and colleagues (Gaggioli, Milani, Mazzoni, \& Riva, 2011) argued that optimal group state is achieved when the team develops a "we-intention", in which the actions of the individuals and of the collective are merged, and the group acts as an autonomous, self-organizing entity.

Following this vision Morris (2005) has recently described how social-networking and pervasive computing technologies can be effectively used to help reduce feelings of social isolation and depression in elderly individuals. In their approach, sensor data measuring phone calls and visits are used to derive public displays of social interactions with relatives and friends, which they introduced into selected 
elders' homes. These ambient displays, which reflect data on remote and face-to-face interaction gathered by wireless sensor networks, are intended to raise awareness of social connectedness as a dynamic and controllable aspect of well-being. According to findings, this strategy was effective in reducing the feeling of social isolation of elderly users.

Key arguments for the usefulness of connectedness in increasing well-being have been presented by Ryff and Singer (2000). The authors argued that interpersonal flourishing (the development of positive relations with other people) is a key dimension of well-being, which is stable across different cultures and time. Furthermore, in a recent paper, Mauri and colleagues (2011) used a variety of physiological data - skin conductance, blood volume pulse, electroencephalogram, electromyography, respiratory activity, and pupil dilation - to evaluate the affective experience evoked by the use of Facebook. The biological signals revealed that Facebook use can evoke a psychophysiological state characterized by high positive valence and high arousal (Core Flow State). These findings support the hypothesis that the successful spread of social networks might be associated with a specific positive affective state experienced by users when they use their account.

Finally, the concept of "social capital" underlines the value of social relationships for the society as a whole: relations among persons facilitate activity and promote well-being (Coleman, 1988; Helliwell \& Putnam, 2004).

Despite the fact that creating and maintaining social relationships is considered a major indicator of well-being and a protective factor for health (House, Landis, \& Umberson, 1988), Western society is characterized by increasing levels of loneliness and lack of social integration. The need of social integration is higher in specific social groups, such as adolescents, disabled, and elderly people. As a consequence, healthcare policies have become increasingly interested in supporting mental health and rehabilitation programs aimed at overcoming social isolation. Information and communication technologies can play a key role in improving these programs.

\subsection{Conclusions: Positive Technology for Personal Growth}

Cyberpsychology is a recent branch of psychology that is driven by the quest to help humans deal with their digital environments. The object of study in cyberpsychology, as it is for much Human-Computer Interaction research, is the change introduced by the technology and not the technology itself. In particular, it aims at the understanding, forecasting and activation of the different processes of change related to the use of new technologies.

Within this broad focus, however, cyberpsychology has two faces. On one side, cyberpsychology tries to understand how technologies can be used to induce clinical change (cybertherapy). On the other side, cyberpsychology focuses on the 
possible use of technology for improving personal development and well-being (positive technology).

In this chapter we introduced and described the "Positive Technology" approach: the scientific and applied approach to the use of technology for improving the quality of our personal experience through its structuring, augmentation and/or replacement - as a way of framing a suitable object of study in the field of personal change (Graffigna, Barello, Wiederhold, et al., 2013; Riva, 2012b; Riva et al., 2012; Wiederhold \& Riva, 2012).

The core psychological background of "Positive Technology" is "Positive Psychology" a nascent discipline whose broad goals are to understand human strengths and virtues, and to promote these strengths in order to allow individuals, communities, and societies to flourish. Specifically, Positive Psychology views optimal functioning as the combination of emotional well-being, social well-being and psychological well-being.

In this chapter we also suggested that it is possible to use technology to manipulate the quality of experience, with the goal of increasing wellness, and generating strengths and resilience in individuals, organizations and society. Firstly, we have classified positive technologies according to their effects on these three features of personal experience (Figure 2):

- Hedonic: technologies used to induce positive and pleasant experiences.

- Eudaimonic: technologies used to support individuals in reaching engaging and self-actualizing experiences.

- Social/Interpersonal: technologies used to support and improve the connectedness between individuals, groups, and organizations.

Additionally, for each level we have identified critical variables - affect regulation for the Hedonic, flow and presence for the Eudaimonic; social presence, collective intentions and networked flow for the Social/Interpersonal - that can be manipulated and controlled to guide the design and development of positive technologies.

Finally, the different examples show that technology can be used to manipulate the features of an experience in three separate but related ways (Figure 2):

- By structuring it using a goal, rules and a feedback system (McGonigal, 2011): The goal provides subjects with a sense of purpose focusing attention and orienting his/her participation in the experience. The rules, by removing or limiting the obvious ways of getting to the goal, push subjects to see the experience in a different way. The feedback system tells players how close they are to achieving the goal and provides motivation to keep trying.

- By augmenting it to achieve multimodal and mixed experiences. Technology allows multisensory experiences in which content and its interaction is offered through more than one of the senses. It is even possible to use technology to overlay virtual objects onto real scenes (Rosenblum, 2000). 
- By replacing it with a synthetic one. Using VR it is possible to simulate physical presence in a synthetic world that reacts to the action of the subject as if he/she was really there. Moreover, the replacement possibilities offered by technology even extend to the induction of an illusion of ownership over a virtual arm or a virtual body (Slater, Spanlang, Sanchez-Vives, \& Blanke, 2010).

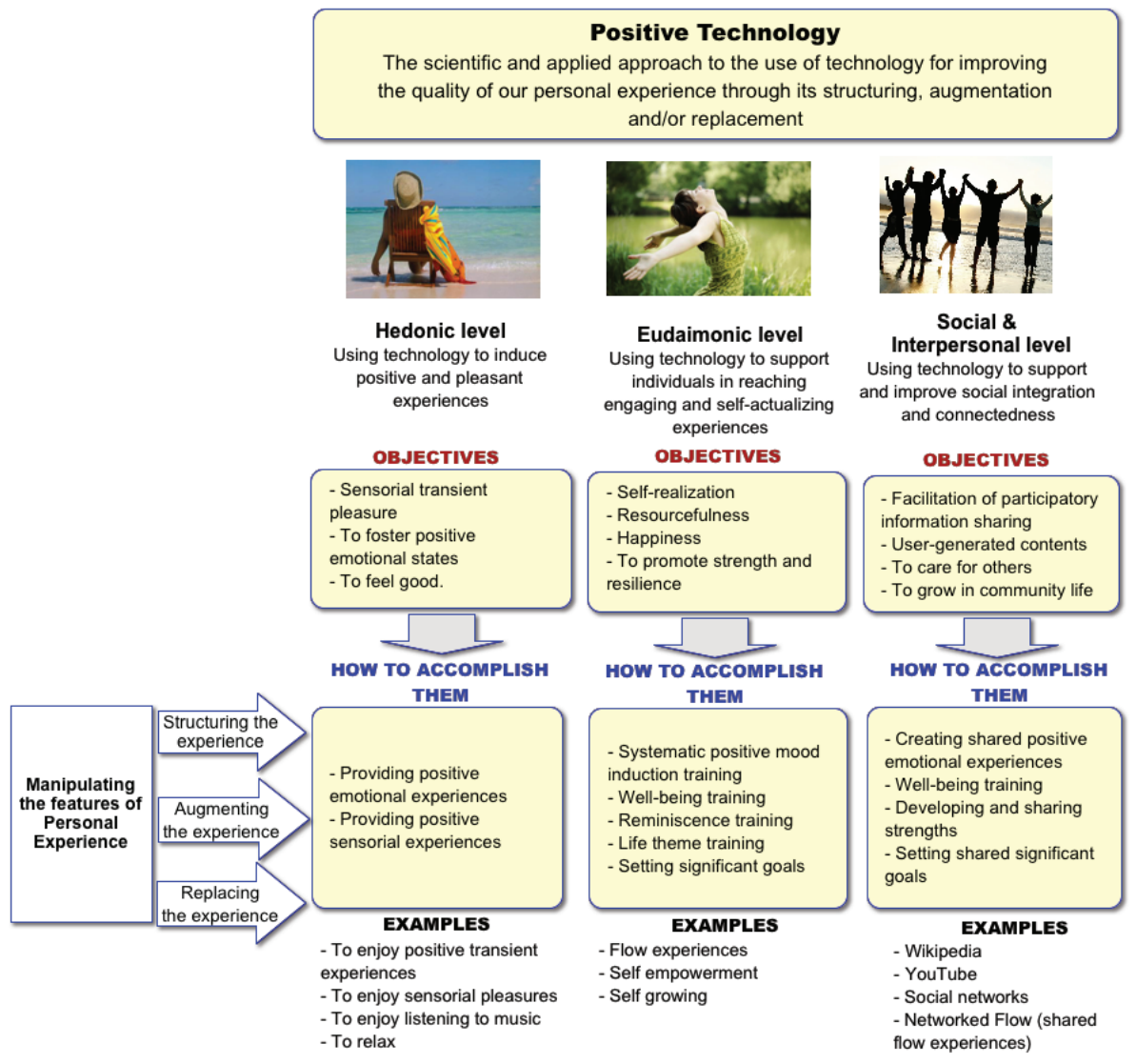

Figure 3.2: Positive Psychology tools (Adapted from Botella et al., 2012)

Even if Positive Techology tools can be used in cybertherapy, too, there is a relevant difference: to be effective, they have to adapt to the specific stage of the change process that the patient is in. As discussed in the first chapter of this book, Kottler (2014), identified a process of change that basically follows this sequence (pp. 19-20):

1. there is an expressed desire for change that is triggered by a crisis, trauma, or developmental transition;

2. a level of pain and discomfort is reached that can't any longer be ignored or

3. denied;

4. there is an awareness or insight that something different must be done; 
5. there is a gradual process of applying what was realized or learned into constructive action; and

6. there is recovery from inevitable relapses.

Within this process, Positive Technologies are successful only if they are able to sustain the patient engagement within the provided experience. Recently, Graffigna and colleagues (Graffigna, 2009; Graffigna, Barello, et al., 2013a; Graffigna, Barello, \& Riva, 2013b; Graffigna, Barello, Wiederhold, et al., 2013) defined "patient engagement" as the experience resulting from the conjoint conative (act), cognitive (think) and emotional (feel) enactment of individuals in their care \& cure management.

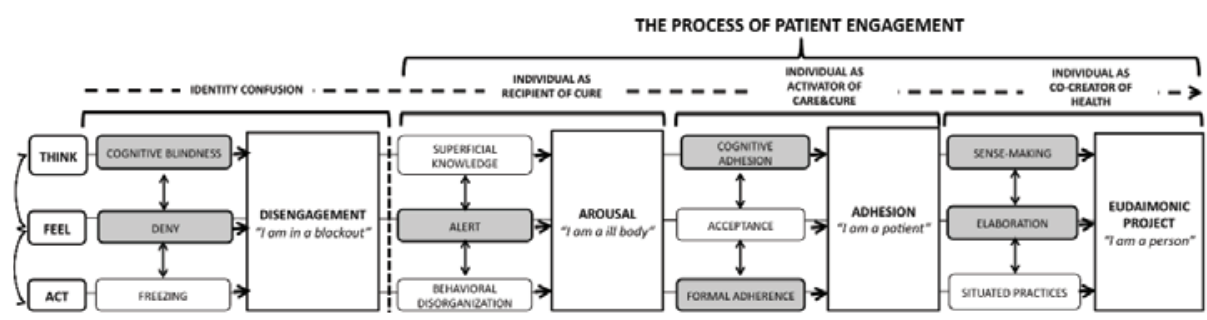

Figure 3.3: The Process of Patient Engagement (Adapted from Graffigna et al., 2013a)

These different experiential dimensions play different (but complementary) driving roles, as key factors for promoting patients' advancement in this sense-making process (see Figure 3). The unachieved synergy among the different subjective dimensions inhibits patients from engaging in their care\&cure management, limiting their potential for obtaining the greatest benefit from the offered Positive Technologies.

\section{References}

Aspinwall, L.G., \& Staudinger, U.M. (Eds.). (2003). A psychology of human strengths: Fundamental questions and future directions for a positive psychology. Washington, D.C.: American Psychological Association.

Botella, C., Riva, G., Gaggioli, A., Wiederhold, B. K., Alcaniz, M., \& Banos, R. M. (2012). The present and future of positive technologies. Cyberpsychology, behavior and social networking, 15(2), 78-84. doi: 10.1089/cyber.2011.0140

Boulos, M.N.K., \& Wheeler, S. (2007). The emerging Web 2.0 social software: an enabling suite of sociable technologies in health and health care education. Health Information and Libraries Journal, 24(1), 2-23.

Castelnuovo, G., Gaggioli, A., Mantovani, F., \& Riva, G. (2003). New and old tools in psychotherapy: The use of technology for the integration of traditional clinical treatments. Psychotherapy: Theory, Research, Practice and Training, 40(1-2), 33-44.

Coleman, J.S. (1988). Social Capital in the creation of human capital. The American Journal of Sociology, 94, S95-S120. 
Csikszentmihalyi, M. (1990). Flow: The psychology of optimal experience. New York: HarperCollins. Damasio, A. (1999). The Feeling of What Happens: Body, Emotion and the Making of Consciousness. San Diego, CA: Harcourt Brace and Co, Inc.

Fredrickson, B. L. (2001). The role of positive emotions in positive psychology. The broaden-andbuild theory of positive emotions. The American psychologist, 56(3), 218-226.

Fredrickson, B. L. (2004). The broaden-and-build theory of positive emotions. Philos Trans R Soc Lond B Biol Sci, 359(1449), 1367-1378. doi: 10.1098/rstb.2004.1512

Gaggioli, A. (2004). Optimal Experience in Ambient Intelligence. In G. Riva, F. Vatalaro, F. Davide \& M. Alcañiz (Eds.), Ambient Intelligence: The evolution of technology, communication and cognition towards the future of human-computer interaction (pp. 35-43). Amsterdam: IOS Press. On-line: http://www.emergingcommunication.com/volume6.html.

Gaggioli, A., Bassi, M., \& Delle Fave, A. (2003). Quality of Experience in Virtual Environments. In G. Riva, W. A. IJsselsteijn \& F. Davide (Eds.), Being There: Concepts, effects and measurement of user presence in synthetic environment (pp. 121-135). Amsterdam: los Press. Online: http:// www.emergingcommunication.com/volume5.html.

Gaggioli, A., Milani, L., Mazzoni, E., \& Riva, G. (2011). Networked Flow: A Framework for Understanding the Dynamics of Creative Collaboration in Educational and Training Settings. The Open Education Journal, 4(Suppl 2:M2), 107-115.

Ghani, J.A., \& Deshpande, S.P. (1994). Task characteristics and the experience of optimal flow in Human-Computer Interaction. The Journal of psychology, 128(4), 381-391.

Gorini, A., Capideville, C.S., De Leo, G., Mantovani, F., \& Riva, G. (2010). The Role of Immersion and Narrative in Mediated Presence: The Virtual Hospital Experience. Cyberpsychology, Behavior and Social Networks, DOI: 10.1089/cyber.2010.0100.

Graffigna, G. (2009). Interpersonal exchanges about HIV-Aids through different media: A crosscultural comparison. Saarbrücken: VDM Verlag.

Graffigna, G., Barello, S., \& Riva, G. (2013a). How to make health information technology effective: the challenge of patient engagement. Archives of physical medicine and rehabilitation, 94(10), 2034-2035. doi: 10.1016/j.apmr.2013.04.024

Graffigna, G., Barello, S., \& Riva, G. (2013b). Technologies for Patient Engagement. Health affairs, 32(6), 1172. doi: 10.1377/hlthaff.2013.0279

Graffigna, G., Barello, S., \& Riva, G. (2013c). Technologies for patient engagement. Health affairs, 32(6), 1172. doi: 10.1377/hlthaff.2013.0279

Graffigna, G., Barello, S., Wiederhold, B. K., Bosio, A. C., \& Riva, G. (2013). Positive technology as a driver for health engagement. Stud Health Technol Inform, 191, 9-17.

Heeter, C. (2003). Reflections on real presence by a virtual person. Presence: Teleoperators and Virtual Environments, 12(4), 335-345.

Helliwell, J.F., \& Putnam, R.D. (2004). The social context of well-being. Philos Trans R Soc Lond B Biol Sci, 359, 1435-1446.

House, J.S., Landis, K.R., \& Umberson, D. (1988). Social relationships and health. Science, 241(4865), 540-545.

Joyce, K.M. (2009). Enhancing Social Presence in Online Learning: Mediation Strategies Applied to Social Networking Tools. Online Journal of Distance Learning Administration, 12(4), online: http://www.westga.edu/ distance/ojdla/winter124/joyce124.html.

Keyes, C.L.M., \& Haidt, J. (Eds.). (2003). Flourishing: Positive Psychology and the Life Well-Lived. Washington, DC: American Psychological Association.

Keyes, C.L.M., \& Lopez, S.J. (2002). Toward a science of mental health: Positive directions in diagnosis and interventions. In C. R. Snyder \& S. J. Lopez (Eds.), Handbook of positive psychology (pp. 45-59). New York: Oxford University Press.

Kottler, J. A. (2014). Change: What really leads to lasting personal transformation. New York, NY: Oxford University Press. 
Marsh, T. (2003). Staying there: an activity-based approach to narrative design and evaluation as an antidote to virtual corpsing. In G. Riva, F. Davide \& W. A. IJsselsteijn (Eds.), Being There: Concepts, effects and measurements of user presence in synthetic environments (pp. 85-96). Amsterdam: IOS Press.

Mauri, M., Villamira, M., Cipresso, P., Balgera, A., \& Riva, G. (2011). Why Is Facebook So Successful? Psychophysiological Measures Describe a Core Flow State While Using Facebook. Cyberpsychology, Behavior and Social Networks, 14(12), 723-731.

McGonigal, J. (2011). Reality Is Broken. Why games make us better and how they can change the world. New York: The Penguin Press.

McNulty, J.K., \& Fincham, F.D. (2012). Beyond Positive Psychology? Toward a contextual view of psychological processes and well-being. American Psychologist, 67(2), 101-110.

Morris, M.E. (2005). Social networks as health feedback displays. IEEE Internet Computing, 9, 29-37.

Park, H. (2010). The Effect Of Activities In Virtual Worlds As A Communication Environment To Understand Each Other. Journal of CyberTherapy \& Rehabilitation, 3(1), 71-82.

Preziosa, A., Grassi, A., Gaggioli, A., \& Riva, G. (2009). Therapeutic applications of the mobile phone. British Journal of Guidance \& Counselling, 37(3), 313-325. doi: 10.1080/03069880902957031

Riva, G. (2004). The psychology of Ambient Intelligence: Activity, situation and presence. In G. Riva, F. Davide, F. Vatalaro \& M. Alcañiz (Eds.), Ambient Intelligence: The evolution of technology, communication and cognition towards the future of the human-computer interaction (pp. 19-34). Amsterdam: IOS Press. On-line: http://www.emergingcommunication.com/volume6. html.

Riva, G. (2009a). Presence as Cognitive Process. In D. Benyon, M. Smyth \& I. Helgason (Eds.), Presence for everyone: A short guide to presence research (pp. 29-31). Edinburgh, UK: Napier University.

Riva, G. (2009b). Virtual reality: an experiential tool for clinical psychology. British Journal of Guidance \& Counselling, 37(3), 337-345. doi: 10.1080/03069880902957056

Riva, G. (2009c). Is presence a technology issue? Some insights from cognitive sciences Virtual Reality, 13(3), 59-69.

Riva, G. (2012a). Personal experience in positive psychology may offer a new focus for a growing discipline. American Psychologist, 67(7), 574-575.

Riva, G. (2012b). What is Positive Technology and its impact on CyberPsychology. Stud Health Technol Inform, 181, 37-41.

Riva, G., Banos, R. M., Botella, C., Wiederhold, B. K., \& Gaggioli, A. (2012). Positive technology: using interactive technologies to promote positive functioning. Cyberpsychology, behavior and social networking, 15(2), 69-77. doi: 10.1089/cyber.2011.0139

Riva, G., Castelnuovo, G., \& Mantovani, F. (2006). Transformation of flow in rehabilitation: the role of advanced communication technologies. Behav Res Methods, 38(2), 237-244.

Riva, G., \& Mantovani, F. (2012). Being There: Understanding the Feeling of Presence in a Synthetic Environment and its Potential for Clinical Change. In C. Eichenberg (Ed.), Virtual Reality in Psychological, Medical and Pedagogical Applications, (pp. 3-34. Online: http://www. intechopen.com/books/virtual-reality-in-psychological-medical-and-pedagogical-applications/ being-there-understanding-the-feeling-of-presence-in-a-synthetic-environment-and-itspotential-for-c). New York: InTech.

Riva, G., \& Mantovani, F. (2014). Extending the Self through the Tools and the Others: a General Framework for Presence and Social Presence in Mediated Interactions. In G. Riva, J.A. Waterworth, \& D. Murray, (Eds.), Interacting with Presence: $\mathrm{HCl}$ and the Sense of Presence in Computer-mediated Environments. (pp. 9-31). Warsaw/Berlin: De Gruyter Open. 
Riva, G., Mantovani, F., Capideville, C. S., Preziosa, A., Morganti, F., Villani, D., . . . Alcaniz, M. (2007). Affective interactions using virtual reality: the link between presence and emotions. Cyberpsychology and Behavior, 10(1), 45-56.

Riva, G., Mantovani, F., \& Gaggioli, A. (2004). Presence and rehabilitation: toward second-generation virtual reality applications in neuropsychology. Journal of Neuroengineering and Rehabilitation, 1(1), 9. doi: 1743-0003-1-9 [pii]

10.1186/1743-0003-1-9

Riva, G., Raspelli, S., Algeri, D., Pallavicini, F., Gorini, A., Wiederhold, B. K., \& Gaggioli, A. (2010). Interreality in practice: bridging virtual and real worlds in the treatment of posttraumatic stress disorders. Cyberpsychol Behav Soc Netw, 13(1), 55-65. doi: 10.1089/cyber.2009.0320 [pii]

Riva, G., Waterworth, J.A., \& Waterworth, E.L. (2004). The Layers of Presence: a bio-cultural approach to understanding presence in natural and mediated environments. Cyberpsychology \& Behavior, 7(4), 405-419.

Riva, G., Waterworth, J.A., Waterworth, E.L., \& Mantovani, F. (2011). From intention to action: The role of presence. New Ideas in Psychology, 29(1), 24-37.

Rosenblum, L. (2000). Virtual and Augmented Reality 2020. leee Computer Graphics and Applications, 20(1), 38-39.

Russell, J.A. (2003). Core Affect and the psychological construction of Emotion. Psychological Review, 110(1), 145-172.

Ryff, C.D., \& Singer, B. . (2000). Interpersonal flourishing: A positive health agenda for the new millennium. Personality And Social Psychology Review, 4, 30-44.

Seligman, M.E.P. (2002). Authentic Happiness: Using the New Positive Psychology to Realize Your Potential for Lasting Fulfillment. New York: Free Press.

Seligman, M.E.P., \& Csikszentmihalyi, M. (2000). Positive psychology. American Psychologist, 55 , 5-14.

Short, J., Williams, E., \& Christie, B. (1976). The social psychology of telecommunications. London: Wiley.

Slater, M., Spanlang, B., Sanchez-Vives, M. V., \& Blanke, O. (2010). First person experience of body transfer in virtual reality. PLoS One, 5(5), e10564. doi: 10.1371/journal.pone.0010564

Swamynathan, G., Wilson, C., Boe, B., Almeroth, K., \& Zhao, B.Y. . (2008). Do social networks improve e-commerce?: a study on social marketplaces. Paper presented at the First Workshop on Online Social Networks, New York, USA.

Villani, D., Lucchetta, M., Preziosa, A., \& Riva, G. (2009). The role of affective media features on the affective response: a virtual reality study. e-Minds: International Journal on Human Computer Interaction, 1(5), 35-55.

Villani, D., Riva, F., \& Riva, G. (2007). New technologies for relaxation: The role of presence. International Journal of Stress Management., 14(3), 260-274.

Waterworth, J.A., Waterworth, E.L., Mantovani, F., \& Riva, G. (2010). On Feeling (the) Present: An evolutionary account of the sense of presence in physical and electronically-mediated environments. Journal of Consciousness Studies, 17(1-2), 167-178.

Wiederhold, B.K., \& Riva, G. (2012). Positive technology supports shift to preventive, integrative health. Cyberpsychology, behavior and social networking, 15(2), 67-68. doi: 10.1089/ cyber.2011.1533

Zahoric, P. , \& Jenison, R.L. (1998). Presence as being-in-the-world. Presence, Teleoperators, and Virtual Environments, 7(1), 78-89. 